\title{
Rehabilitasyon Çalışanlarının Aile İşlevselliğine Yönelik Görüşleri Üzerine Nitel Bir Çalışma
}

\author{
A Qualitative Research on the views of Rehabilitation Staff About the Family Functioning
}

\author{
Hatice ABAOĞLU ${ }^{1}$, Esra, AKI $^{2}$ \\ ${ }^{1}$ PT, Ph.D., Faculty of Health Sciences, Occupational Therapy Department, Hacettepe University, Ankara, Turkey \\ ${ }^{4}$ Ph.D. Prof, Faculty of Health Sciences, Occupational Therapy Department, Hacettepe University, Ankara, Turkey.
}

\section{ÖZ}

Amaç: Bu araştırmanın amacı, rehabilitasyon yaklaşımlarında özel gereksinimli çocuğa sahip ailelerin işlevselliğini rehabilitasyon çalışanlarının görüşleri doğrultusunda analiz etmekti. Gereç ve Yöntem: Araştırma, nitel araştırma desenlerinden biri olan durum çalışması olarak tasarlandı. Rehabilitasyon alanında en az bir yıldır çalışan farklı meslek gruplarından (fizyoterapist, psikolog, çocuk gelişimi uzmanı, okul öncesi öğretmeni, ergoterapist, sosyal hizmet uzmanı ve hekim) oluşan 100 birey araştırma grubunu oluşturdu. Araştırmacılar tarafından geliştirilen yarı yapılandırılmış görüşme formu, veri toplama aracı olarak kullanıldı. Verilerin analizinde içerik analizi tekniğinden yararlanıldı. Sonuçlar: Araştırmanın sonucunda elde edilen veriler ışığında, rehabilitasyon çalışanlarının, özel gereksinimi olan çocukların tedavisinde ailenin önemli katkıları olduğuna inandığı ve çocukların günlük yaşamdaki bağımsızlığının ancak aile katılımı ile gerçekleşebileceği görüşünde olduğu saptandı. Tartışma: Bu araştırmanın bulguları, sağlık hizmetleri ve rehabilitasyon uygulamalarında giderek yaygınlaşan aile temelli yaklaşımları destekler niteliktedir. Rehabilitasyon çalışanlarının görüşleri, aile katılımının çocuk, aile ve rehabilitasyon açısından önemli ve etkili olduğu yönündedir. Aile katılımını etkileyen faktörlerin ayrıntılı incelendiği daha kapsamlı çalışmalara ihtiyaç vardır.

Anahtar Kelimeler: Çocuk; Ebeveynler; Rehabilitasyon; Niteleyici araştırma

\section{ABSTRAC T}

Purpose: The aim of this study was to analyze rehabilitation staff views about the functioning of families of children with special needs in rehabilitation approaches. Material and Methods: The study was designed as a case study which is one of the qualitative research designs. The study group consisted of 100 individuals from different occupational groups (physiotherapists, psychologists, child development specialists, preschool teachers, occupational therapists, social worker and physician) working in the field of rehabilitation for at least a year. A semi-structured interview form developed by the researchers was used as a data collection tool. In the analysis of the data, content analysis technique was used. Results: The results of the study showed that rehabilitation staff believed that family members were important contributors to the treatment of children with special needs and that children's independence in daily life could only be achieved through family involvement. Conclusion: The findings of this study support family-based approaches that are becoming increasingly common in health care and rehabilitation applications. The views of rehabilitation staff suggest that family involvement is important and effective for children, families and rehabilitation. There is a need for more extensive studies that examine in detail the factors affecting family involvement.

Key Words: Child; Parents; Rehabilitation; Qualitative research 
"Özel gereksinimi olan çocuklar" ifadesi, çocuklar arasındaki bireysel farklılıklar göz önünde bulundurularak, öğrenme ve davranış problemleri, bedensel, duyusal yetersizliği olan ya da zihinsel olarak üstün, özel yetenekli çocukları da içerisine alan, tipik gelişim gösteren çocuklardan farklılığı ifade eden kapsamlı bir terimdir (Eripek, 2005). Özel gereksinimi olan çocuklar, çok sayıda sağlık uzmanının birlikte yer aldığı, farklı tedavi yaklaşımlarını içeren uzun süreli sağlık ve rehabilitasyon hizmetlerine ihtiyaç duyarlar. Sağlık eğitimi ve destekleme, görme, işitme, konuşmanın değerlendirilmesi, fiziksel ve psikososyal faktörlerin incelenmesini içeren koruyucu ve birincil bakım hizmetleri, özelleşmiş terapatik yaklaşımlar, habilitasyon ve rehabilitasyon hizmetleri, özel gereksinimi olan çocukların ihtiyaç duyabileceği sağlık hizmetleri arasındadır (Newacheck ve Kim, 2005; Denboba, McPherson, Kenney ve ark, 2006).

Çocuğun gelişiminde ve sosyal katılımında ailenin önemli bir rolü vardır. Çocuk doğduğu andan itibaren ailenin davranış ve deneyimlerinin etkisi altında kalır. Beden dili, sözlü ifadeler ödül veya ceza yoluyla aileler çocukların davranışlarını şekillendirebilir (Haywood, 1993). Özel gereksinimleri olan bir çocuğun anne babası olma rolü, ailelerin hazır olmadığı bir durumdur ve büyük çoğunluğunda, çok sayıda duygusal (stres, mutsuzluk, vb.) ve toplumsal (toplumdan soyutlanma, vb.) soruna yol açabilmektedir. Aile üyelerinden birinin herhangi bir yetersizlik nedeniyle rollerini yerine getirememesi tüm ailenin uyumunu etkilemekte ve dengeleri sarsabilmektedir. Uzun süreli tıbbi, eğitimsel müdahaleler ve rehabilitasyon hizmetlerini gerektiren bu süreç, ailelerin işlevlerini sınırlandırmakta ve zorlanmalara neden olabilmektedir (Kırbaş ve Özkan, 2013; Doğan, 2014; Coşkun ve Akkaş, 2009).

Özel gereksinimi olan çocuklara verilen sağlık hizmetlerine bütün aile bireyleri bir şekilde dahil olur. Aile, özel gereksinimi olan bir çocuğun yaşamında sürekli olarak rol alır ve çocuğunun yetenek ve intiyaçlarının farkına varır. Tedaviler, eğitim hizmetleri ve genel tıbbi kontrollere katılma, ilaçların, cihazların, eğitim materyallerinin kullanımı gibi pek çok sorumluluğa sahip olan aileler, çocukların doğal ortamlarında öğrenmelerini destekleme, okul ve toplum yaşamına katılımlarını sağlamada önemli bir rol üstlenirler. Bu nedenle, ailelerin seçimlerini ve desteğini kabul ederek onları karar verme ve işbirliği sürecine dahil etmek, çocukları için daha güçlü bir hizmet sağlayacaktır (Hostler, 1999; Schmidt, Garrat ve Fitzpatrick, 2002; King, Teplicky, King ve ark, 2004).

Son yıllarda aile merkezli uygulamalar ile birlikte, aileler, klinikteki uygulamaları ev ortamında ve toplum içerisinde sürdürerek rehabilitasyon çalışmalarında daha aktif yer almaya başlamışlardır (Jansen, Ketelaar ve Vermeer, 2003). Rehabilitasyon çalışanlarının, özel gereksinimi olan bir çocuğun rehabilitasyonunda ailenin rolünün hakkında farkındalığı olmakla birlikte, çoğu ailenin bakım verme rolü hakkındaki bilgisi yetersizdir. Aile merkezli değerlendirmeler rehabilitasyonda ailenin rolünün önemini göz önünde bulundurmalıdır. Ailenin desteği, uzun dönemli rehabilitasyonun başarısını etkileyerek ve engellilikle birlikte pozitif yaşam olanağı kazandırarak sağlık ve iyilik haline katkıda bulunur (Mpofu, Levers, Mpofu ve ark, 2014).

Konu ile ilgili literatür incelendiğinde ailelerin rehabilitasyon hizmetlerine değişen düzeylerde katılım gösterdikleri ve bu katılımı pek çok faktörün etkilediği görülmüştür. Araştırmalar ailelerin sağlık hizmetleri ile ilgili karar verme sürecine daha fazla dahil olmak istediklerini göstermektedir. Sağlık çalışanlarının yaklaşımı ve iletişimi ailenin katılım düzeyini etkilemektedir (Aarthun ve Akerjordet, 2014). Özel gereksinimi olan çocukların rehabilitasyonunda ailenin, ekibin bir parçası olarak değerlendirme ve müdahale sürecinde yer almasının önemini vurgulayan aile merkezli yaklaşımlara olan ilgi giderek artıyor olsa da özel gereksinimli çocuklar ve aileleri ile doğrudan temasta olan farklı mesleklerden rehabilitasyon çalışanlarının ortak noktada birleşen görüşleri doğrultusunda inceleyen kültürümüze özgü bir araştırmaya rastlanmamıştır. Bu araştırma özel gereksinimli çocuğa sahip ailelerin rehabilitasyon sürecindeki işlevselliğini rehabilitasyon alanında çalışan farklı disiplinlerden bireylerin görüşleriyle analiz etmek amacıyla planlanmıştır.

\section{GEREÇ VE YÖNTEM}

Bu araştırma nitel araştırma yöntemlerinden biri olan durum çalışması deseninde tasarlandı. Nitel araştırma, gözlem, görüşme ve doküman analizi gibi veri toplama teknikleri kullanılarak algıların ve olayların doğal ortamda gerçekçi ve bütüncül bir şekilde ortaya konduğu araştırma türüdür (Yıldırım ve Şimşek, 2011). Araştırmanın veri toplama aracı olarak görüşme tekniği kullanıldı. Görüşmelerin yazıya dökülmesi ile oluşturulan veri setlerinin analizi nitel veri analizi tekniklerinden içerik analizi kullanılarak yapıldı. İçerik analizi, nitel araştırmalarda yaygın olarak kullanılan bir tekniktir. Sözel, yazılı ya da diğer materyallerin nesnel ve sistematik bir şekilde incelenmesini ifade eden bilimsel bir yaklaşımdır (Yıldırım ve Şimşek, 2011).

$$
\text { Araştırmaya katılacak rehabilitasyon }
$$
çalışanlarının seçiminde amaçlı örnekleme yöntemlerinden biri olan tipik durum örneklemesi kullanıldı. Pediatrik rehabilitasyon alanında çalışan sağlık profesyonelleri ile görüşülerek araştırma hakkında detaylı bilgi verildi. Özel gereksinimi olan çocukların rehabilitasyonunda en az bir yıl deneyime 
sahip ve gönüllü olarak katılmayı kabul eden bireyler araştırmaya alındı. Araştırmaya, yaş ortalamaları 29,41 \pm 6,55 yıl olan, 39'u erkek (\%39), 61 'inin kadın (\%61), fizyoterapist, psikolog, çocuk gelişimi uzmanı, okul öncesi öğretmeni, ergoterapist, sosyal hizmet uzmanı ve hekimden oluşan 100 sağlık çalışanı dahil edildi. Araştırma Helsinki Bildirgesi'ne uygun olarak planlandı ve bireylere aydınlatılmış onam formu imzalatıldı. Araştırmanın etik olarak uygunluğu için Hacettepe Üniversitesi Girişimsel OImayan Klinik Araştırmalar Etik Kurulu'ndan izin alındı.

Araştırmaya dahil edilen rehabilitasyon çalışanlarının yaş, cinsiyet, meslek, çalışma süresi ve çalışılan kurum gibi sosyodemografik özellikleri kaydedildi. Konu ile ilgili literatür incelendikten sonra araştırmacılar tarafından hazırlanan, rehabilitasyon çalışanlarının rehabilitasyon alanında ailenin rolü hakkındaki görüşlerini ve aileden beklentilerini içeren yarı yapılandırılmış bir görüşme formu hazırlandı. Gönüllü olarak araştırmaya katılmayı kabul eden bireyler ile, istek ve beklentilerine uygun ortam ve zamanda, dikkat dağınıklığı ve konsantrasyon güçlüğü gibi sonuçları etkileyebilecek faktörler ortadan kaldırılarak yüz yüze görüşmeler gerçekleştirildi. Görüşme formunda belirlenen temel soru 'Rehabilitasyon programına aileyi dahil etme hakkında ne düşünüyorsunuz?' şeklindeydi.

Rehabilitasyon çalışanları ile yapılan görüşme sonrası kayıt edilen verilerde yer alan ifadeler araştırmacılar tarafından okunarak incelendi. Veriler taranarak, benzerliklerine göre düzenlendi ve temalar elde edildi. Görüşme tekniği ile elde edilen bulgular yorumlandı ve verilerin bir kısmı uygun olduğu durumda, sayısallaştırılarak frekans ve yüzdelik dağılımlar verildi.

\section{SONUÇLAR}

Rehabilitasyon çalışanlarının demografik özellikleri incelendiğinde, eğitim durumuna göre 58'i (\%58) lisans, 34'ü (\%34) yüksek lisans ve 8'i doktora mezunuydu. Meslek dağılımında bireylerin 66'sı (\%66) fizyoterapist, 6'sı (\%6) psikolog, 20'si çocuk gelişimi uzmanı, 4'ü (\%4) okul öncesi öğretmeni, 2'si (\%2) ergoterapist, 1'i (\%1) sosyal hizmet uzmanı ve 1 'i (\%1) de hekimdi. Araştırmaya katılan rehabilitasyon çalışanlarının çalışma alanları incelendiğinde, bireylerin çoğunun (\%49) özel eğitim merkezinde çalıştığı görüldü. Çalışma süreleri değerlendirildiğinde, 51'inin (\%51) 1-5 yıl arasında ve 9'unun (\%9) 21 yıl ve üzeri mesleki deneyime sahip olduğu belirlendi. Rehabilitasyon çalışanlarının demografik özellikleri Tablo 1'de verildi.

Elde edilen sonuçlara göre, çalışmaya katılan bireylerin tamamı rehabilitasyon programına aileyi dahil etmenin gerekli olduğunu düşünüyordu. Yapılan görüşmelerin içerik analizi sonrasında bireylerin rehabilitasyon programlarına aileyi dahil etme konusundaki düşünceleri incelenerek çocuk, aile ve rehabilitasyon açısından benzer alt temalar bir araya getirildi ve iki ana tema (aile işlevselliğinin etkileri ve önemi) oluşturuldu. Sonuçlar aşağıdaki gibi özetlendi (Şekil 1).

Tablo 1. Rehabilitasyon çalışanlarının demografik özellikleri

\begin{tabular}{|l|l|c|}
\hline \multicolumn{2}{|c|}{ Demografik Özellik } & $\mathbf{n = 1 0 0}$ \\
\hline Cinsiyet & Kadın & 61 \\
& Erkek & 39 \\
\hline Eğitim & Lisans & 58 \\
Durumu & Yüksek Lisans & 34 \\
& Doktora & 8 \\
\hline Meslek & Fizyoterapist & 66 \\
& Psikolog & 6 \\
& Çocuk Gelişimi Uzmanı & 20 \\
& Okul Öncesi Öğretmeni & 4 \\
& Ergoterapist & 2 \\
& Sosyal Hizmet Uzmanı & 1 \\
& Hekim & 1 \\
& & \\
\hline Çalışma Alanı & Özel Eğitim Merkezi & 49 \\
& Üniversite & 34 \\
& Hastane & 17 \\
\hline Çalışma & $1-5$ yıl & 51 \\
Süresi & $6-10$ yıl & 23 \\
& $11-15$ yıl & 13 \\
& $16-20$ yıl & 4 \\
& 21 yıl ve üzeri & 9 \\
\hline
\end{tabular}

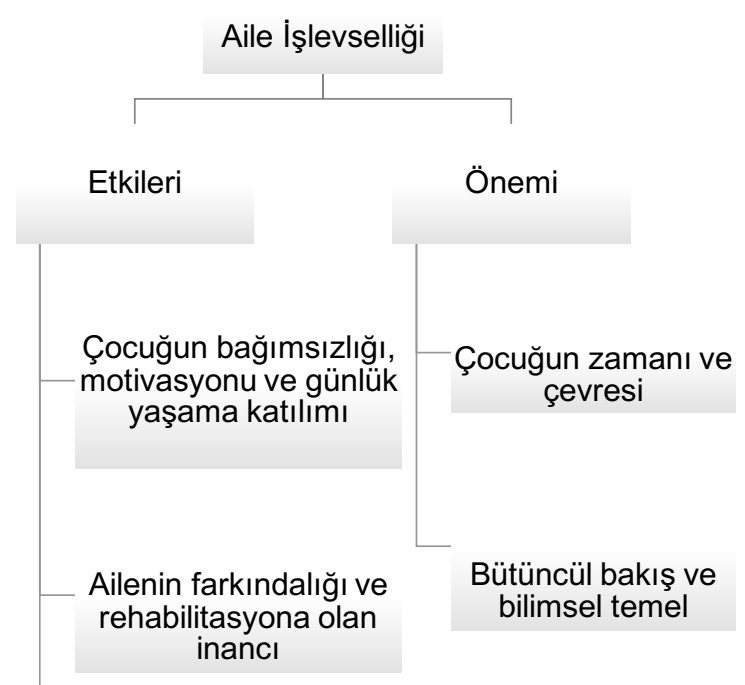

Rehabilitasyonun etkinliği, sürekliliği ve günlük yaşama uyarlanması

Şekil1. Aile İşlevselliğiyle İlgili Temalar 
Aile İşlevselliğinin Etkileri

Çocuğun bağımsızlığı, motivasyonu ve günlük yaşama katılımı

Araştırmaya katılan rehabilitasyon çalışanlarından otuz dördü (\%34), özel gereksinimi olan çocuğun günlük yaşam aktivitelerindeki bağımsızlığını artırmanın ailenin katılımı ile mümkün olacağını düşünüyordu. Yirmi beş katılımcı (\%25), çocuğun fonksiyonelliğinin sağlanmasında ailenin rolünün çok önemli olduğunu vurguladı. Otuz dört (\%34) katılımcı, rehabilitasyon sürecinde çocuğun motivasyonunun ancak aile desteği ile mümkün olabileceği görüşündeydi.

Katılımcıların görüşlerine göre, aile işlevselliği çocuğun bağımsızlığı, motivasyonu ve günlük yaşama katıımını etkileyebilmektedir. Bazı görüşler şu şekildeydi:

'Rehabilitasyon süreci bazen yorucu, uzun ve bunaltıcı olabilir. Bu tür durumlarda hastanın motivasyonunu yüksek tutabilmek için gerekli faktörlerden birisinin de kişinin ailesi olduğunu düşünüyorum.' (Katıımcı 14, fizyoterapist)

'...bireyin tam fonksiyonelliğini sağlamak, doğal yaşam alanında yardımı da gerektirir.' (Katılımcı 60, fizyoterapist)

'Program sadece aileye yol göstermek içindir. Çocukla vakit geçiren en çok aile olduğu için, çocuğun kazanımlarını günlük yaşama aktarabilmek için ailenin katılımı şart.' (Katılımcı 58, fizyoterapist)

Ailenin farkındalığı ve rehabilitasyona olan inancı

Yirmi yedi katılımcı (\%27), rehabilitasyon programlarına dahil edilmenin, ailenin tedaviye olan inancını kuvvetlendirdiğini ve çocuğuna olan desteğini artırmasını sağladığını belirtti. On dokuzu (\%19) aile rehabilitasyona dahil edildiğinde, çocuğunun durumunu anlayıp kabullenmesinin kolaylaştığını, yirmi ikisi (\%22) ise ailenin özel gereksinimi olan çocuğunun potansiyeli hakkında farkındalığının arttığını ifade etti.

Katılımcılar, ailenin rehabilitasyona dahil olmasının onların süreci kabullenerek, farkındalıklarında ve tedaviye olan inançlarında artış sağladığı düşüncesindeydi. Bazı katılımcı görüşleri aşağı verildi:

‘llk olarak ailenin mevcut sorunu sahiplenmesi ve sorunu kabullenmesi açısından ailenin dahil edilmesi gereklidir.' (Katılımcı 18, okul öncesi öğretmeni)

'Ailenin programla ilgili bilgi sahibi olması katılımını güçlendirir. Böylece hasta olan yakınına karşı destek sağlar. Tedaviye inançları artar.' (Katılımcı 15, psikolog)

'...aile dahil olmalıdır. Bu sayede çocuğun ihtiyaçları, hastalığı, gereksinimleri hakkında ailenin bilgisi olur.' (Katılımcı 37, fizyoterapist)
Rehabilitasyonun etkinliği, sürekliliği ve günlük yaşama uyarlanması

Katılımcılardan kırk üçü (\%43), beklenen sonuçlara ulaşmanın ancak ailenin rehabilitasyona aktif katılımı ile mümkün olabileceğini, kırk yedisi (\%47), rehabilitasyonun etkinliği, kalıcı olması ve yaşama uyarlanabilmesi için aile önemli bir rol üstlendiğini ve yine kırk üçü (\%43), ailenin katkısının rehabilitasyon çalışmalarının etkinliğini hızlandırdığını ifade etti. Yirmi yedi katılımcı (\%27), öğrenmenin her zaman ve her ortamda devam ettiğini ve sürekliliğin olması gerektiğini, otuz yedi katılımcı (\%37) ise, rehabilitasyon merkezindeki müdahalelerin etkinliğinin çocuğun tüm yaşamına yaygınlaştırımasında ailenin katılımının önemli olduğunu söyledi.

Katılımcılar, aile katıımının rehabilitasyonun etkinliği, sürekliliği ve günlük yaşama uyarlanmasını etkilediğini ifade ettiler. Bazı ifadeler aşağıdaki gibidir:

'Türkiye şartlarında rehabilitasyon için verilen süre yeterli değildir evde desteklenmesi gerekir ve kişinin kazanılması istenen yeteneklerini günlük yaşamına aktarması için aile gereklidir.' (Katılımcı 76, ergoterapist)

'Eğitim her zaman ve her yerde devam eden bir süreç olduğu için, sadece belli yerlerde desteklendiğinde süreklilik vermemektedir.' (Katıımcı 22, çocuk gelişimi uzmanı)

'Ailenin dahil olmadığı hiçbir tedavi programı başarılı olamaz.' (Katılımcı 75, hekim)

'Aile-rehabilitasyon-okul üçgeninde daha etkili sonuçlar elde edilir.' (Katılımcı 59, psikolog)

\section{Aile İşlevselliğinin Önemi}

\section{Çocuğun zamanı ve çevresi}

Katılımcılardan kırk altısı (\%46), özel gereksinimi olan çocuklar zamanlarının büyük çoğunluğunu aileleri ile birlikte geçirdiklerini ifade etti. Kırk beş katılımcı (\%45), rehabilitasyonun evde de aile ile birlikte devam etmesi gerektiğini, yirmi yedi katılımcı (\%27), bireyin sosyal, kültürel ve fiziksel çevresinden ayrı düşünülemeyeceğini belirtti.

Katılımcılar, ailenin çocuğun zamanının çoğunu birlikte geçirdiği sosyal çevresini oluşturması açısından aile işlevselliğinin önemli olduğunu düşünüyorlardı. Bu görüşle ilgili bazı ifadeler şu şekildeydi:

'Çocuğun evde ailesiyle geçirdiği vakit neredeyse hayatının tamamını oluşturuyor.' (Katılımcı 23, fizyoterapist)

'Özel eğitim merkezlerinde çocuğun fizyoterapi aldığı süre evde geçirdiği sürenin yüzde biri kadar bile etmiyor. Gerçekten hesapladım. Çocuğun evinde ailesiyle geçirdiği süre rehabilitasyonun etkinliği için daha geçerli. Bu yüzden aileyi dahil etmek programın etkinliği açısından gereklidir.' (Katılımcı 30, fizyoterapist)

'Rehabilitasyonda başarının anahtarı ailedir. Aile çocuğun gün boyu programının uygulanmasından 
sorumludur.' (Katılımcı 43, çocuk gelişimi uzmanı)

\section{Bütüncül bakış ve bilimsel temel}

Yirmi sekiz katılımcı (28), aile ile birlikte çalışmanın rehabilitasyon programına bütüncül bakış açısı sağlayacağını, on bir katılımcı (\%11), bu alanda yapılan pek çok araştırmanın ailenin rehabilitasyondaki önemini vurguladığını ifade etti.

Katılımcılar rehabilitasyonda aile işlevselliğinin bütüncül bir bakış açısı sağladığı ve bilimsel araştırmalarla desteklendiği için önemli olduğunu belirtti. Bununla ilgili olarak bir katılımcı şöyle söyledi:

'Bilimsel araştırmalar ailenin de rehabilitasyona katılması gerektiğini savunuyor. ICF'e göre çevresel faktörlerin sağlık üzerine etkisi gösterilmektedir. Aile önemli bir çevresel destek sistemidir. (Katılımcı 28, fizyoterapist)

\section{TARTIŞMA}

Fiziksel engelli çocukların günlük yaşama katılımına fırsat veren aile davranışları, sorunları ve intiyaçlarına yönelik bir derleme çalışmasında, çocukların katılımını ailelerin nasıl destekledikleri ve nelere intiyaç duydukları hakkında mevcut literatür incelenmiştir. Araştırma, fiziksel ve sosyal çevredeki kısıtlanmalardan dolayı çocuklarının katılımını destekleme konusunda ailelerin çok fazla sorun yasadıklarını ortaya koymuştur. Araştırmacılar, ailelerin çocuklarını ne ölçüde destekledikleri ve bu destek için nelere intiyaç duyduklarının daha kapsamlı bir şekilde incelenmesi gerektiğini ve aile merkezli yaklaşımı benimseyen profesyonellerin ebeveynleri bu konuda desteklemeye yeterince dikkat edip etmediklerini sorgulamaları gerektiğini belirtmişlerdir (Piskur, Beurskens, Jongmans ve ark, 2012). Bu araştırmaya katılan rehabilitasyon çalışanlarının tamamı literatürde öne çıkan görüşlere benzer şekilde aile katılımının öneminin farkındadır ve ailenin rehabilitasyona dahil edilmesi gerektiğini düşünmektedir.

Hallström, Runeson ve Elander (2002), yaptıkları çalışmada, ailelerin çocukların sağlık bakımı ile ilgili kararlara ne ölçüde katıldığını belirlemeyi ve ailenin katılım derecesini etkileyen faktörleri tanımlamayı amaçlamışlardır. Beş ay- 18 yaş arası çocukların ve ailelerin gözlenmesi ile yapılan nitel analiz sonucu ailelerin değişen düzeylerde katılım gösterdikleri, bazı ailelerin ihtiyaçlarını belirtirken kendilerini ifade etmekte güçlük yasadıkları görülmüşs ve sağlık çalışanlarının onlara daha açık olması ve intiyaçlarını anlayabilmesi gerekliliği vurgulanmıştır. Aile merkezli bakım kavramının boyutlarını ve bunların birbiri ile ilişkisini tanımlayan kavramsal bir çerçeve geliştirmek amacıyla tasarlanan bir çalışmada, otuz yedi aile ve 16 uzmanla yapılan görüşme ve odak grup sonucunda ailelerin çocuk ve aileye en iyi şekilde katkıda bulunacak sağlık uygulamalarına uzmanlarla işbirliği yaparak dahil olmak istedikleri görülmüştür (MacKean, Thurston, ve Scott, 2005). Son yıllarda özel gereksinimi olan çocukların rehabilitasyon programına yönelik araştırmalar incelendiğinde kabul gören yaklaşımlar terapist ve ailenin iş birliği içerisinde olduğu, çocuğu ve aileyi bütün olarak gören ve hedefleri bu doğrultuda belirleyen müdahale yöntemleridir (Kuhlthau, Bloom, Van Cleave ve ark, 2011). Çalışmamızda, aile ve çocuğun bütüncül bir bakış, açısı ile değerlendirilmesi gerektiği ve ailenin rehabilitasyona dahil olmasının bilimsel araştırmalarla desteklendiği sonucuna varılmıştır.

Rehabilitasyon sürecine ailenin dahil edilmesiyle ilgili fizyoterapistlerin algısını değerlendiren bir çalışmada, aile katılımını kolaylaştıran ve engelleyen faktörler fizyoterapistlerin bakış açısıyla incelenmiştir. Çalışmada, aile katılımının rehabilitasyonun önemli bir belirleyicisi olduğu ve ailenin bilgi, davranış ve beceri düzeyinin rehabilitasyona katılımı etkilediği sonucuna varılmıştır (Ryan, Wade, Nice ve ark, 1996). Araştırmamızda da, bu bulguları destekleyici şekilde, rehabilitasyona katılımın ailenin bilgi ve farkındalık düzeyini artırdığı sonucuna ulaşımıştır. Ancak aile katılımının çok sayıda faktörden etkilenen ve farklı göstergeleri olan karmaşık bir süreç olduğu düşünülmektedir.

Kırk sekiz çalışmanın meta analizinin yapıldığı bir çalışmada, aile katılımının çocuğun psikoterapi sonuçlarına etkisi bireysel çocuk müdahaleleri ve ebeveyn- çocuk müdahaleleri karşılaştırılarak incelenmiş ve çocuğun psikoterapi sonuçları açısından ebeveyni içeren müdahaleler lehine anlamlı sonuçlar bulunmuştur (Dowell ve Ogles, 2010). Otizm tanılı çocuklara yönelik erken müdahale programlarına ebeveynin katılımı ile ilgili sağlık uzmanlarının algısını araştıran nitel bir çalışmada, ebeveyn katılımının eksikliğinin, çocuğun erken müdahale programı kapsamındaki gelişimi ve ilerlemesini, ihtiyaçlarını destekleme ve becerilerini farklı ortamlara genelleyebilme yeteneğini olumsuz yönde etkilediği gösterilmiştir (Bennett, 2012). Serebral Palsili çocuklarda on iki seanslık müdahale sırasında ve sonrasında aile katılımının çocuğun performansı ve öz yeterliği ile ilişkisinin araştırıldığı bir başka çalışmada, performans ve öz yeterlik sonuçlarında anlamlı bir fark bulunmuş ancak dört aylık takipte bu sonuçların tersine döndüğü görülmüştür (Craig, 201). Araştırmamızın sonuçları da literatürdeki yaygın görüşle benzer şekilde, çocuğun bağımsızlığı, motivasyonu ve günlük yaşama katılımının, rehabilitasyon programlarının etkinliği, sürekliliği ve günlük hayata uyarlanabilirliğinin ancak aile katılımı ile mümkün olabileceğini desteklemektedir. Ancak bu ilişkilerin daha ayrıntılı araştırılmasına intiyaç vardır. 
Katılımcı sayısı ve farklı disiplinleri içermesi bu araştırmanın güçlü yönüdür. Literatüre destekleyici önemli bilgiler sunsa da araştırmamızın bazı limitasyonları vardır. Araştırma grubunda yer alan rehabilitasyon çalışanlarının uzmanlık alanları açısından sayısal anlamda eşit olmaması araştırmanın sonuçlarını etkileyebilir. Araştırma, uzmanların aile katılımıyla ilgili görüşleriyle sınırlıdır. Bu katılımının ne ifade ettiği ya da hangi faktörlerden etkilendiği araştırma kapsamında değerlendirilmemiştir.

Sonuç olarak, aile katılımının çocuklara ve ailelere bazı yararlar sağladığı ve bu katılımın sağlık uzmanları tarafından pediatrik rehabilitasyonun önemli bir parçası olarak desteklendiği söylenebilir. Özel gereksinimi olan çocukların rehabilitasyon programının evde ve çocuğun tedavi seansları dışındaki zamanlarında da sürdürülmesi önemlidir. Zamanlarının büyük çoğunluğunu aileleri ile geçiren bu çocuklar için rehabilitasyonun etkinliği, kalıcılığı ve günlük yasama uyumlandırılabilir olmasında ailenin katkısı büyüktür. Aileler, rehabilitasyon programlarına dahil edildiğinde çocuğun durumunu anlayıp kabullenmeleri ve tedaviye inançlarının kuvvetlenmesi sağlanabilir. Ailelerin rehabilitasyona aktif katılımı çocukların motivasyonunu ve rehabilitasyon çalışmalarının etkinliğini artırabilir. İleriki çalışmalar için, aile katılımının etkileyen çok boyutlu faktörlerin kapsamlı bir şekilde incelenmesi ve buna yönelik müdahaleler yapılması önerilmektedir.

\section{KAYNAKLAR}

Aarthun, A. \& Akerjordet, K. (2014). Parent participation in decision- making in health-care services for children: an integrative review. J Nurs Manag, 22(2), 177-191.

Bennett, A. (2012). Parental involvement in early intervention programs for children with autism. Master of Social Work Clinical Research Papers, St. Catherine's University. Retrieved from the Web December 10, 2017.

http://sophia.stkate.edu/cgi/viewcontent.cgi?article=1113\&c ontext=msw_papers

Coşkun, Y. \& Akkaş, G. (2009). Engelli çocuğu olan annelerin sürekli kaygı düzeyleri ile sosyal destek algıları arasındaki ilişki. Ahi Evran Üniversitesi Kırşehir Eğitim Fakültesi Dergisi, 10(1), 213-227.

Craig, T. M. (2016). Exploring correlations between parent involvement and performance and self efficacy outcomes in children with cerebral palsy. (Doctoral dissertation). University of Toronto, Canada.

Denboba, D., McPherson, M. G., Kenney, M. K., Strickland, B. \& Newacheck, P. W. (2006). Achieving family and provider partnerships for children with special health care needs. Pediatrics, 118(4), 1607-1615.

Doğan, M. (2014). Yetersizliği olan çocuklar, aile ve aile eğitimi: kavramsal ve uygulamaya dönük gelişmeler. Abant Izzet Baysal Üniversitesi Eğitim Fakültesi Dergisi, 15(Özel Sayı), 111-127.
Dowell, K. A. \& Ogles, B. M. (2010). The effects of parent participation on child psychotherapy outcome: a metaanalytic review. J Clin Child Adolesc Psychol 39(2), 151162.

Eripek, S. (2005). Özel gereksinimi olan çocuklar ve özel eğitim. S. Eripek (Ed). Özel eğitim. Eskişehir: Anadolu Üniversitesi Açık Öğretim Fakültesi Yayınları, Ünite 1, 114.

Hallström, I., Runeson, I. \& Elander, G. (2002). An observational study of the level at which parents participate in decisions during their child's hospitalization. Nursing Ethics, 9(2), 202-214.

Haywood, K.M. (1993). Life span motor development. Human Kinetics Publisher, Windsor.

Hostler, S.J. (1999). Pediatric family-centered rehabilitation. J Head Trauma Rehabil, 14, 384-393.

Jansen, L., Ketelaar, M. \& Vermeer, A. (2003). Parental experience of participation in physical therapy for children with physical disabilities. Dev Med Child Neurol, 45, 5869.

King, S., Teplicky, R., King, G. \& Rosenbaum, P. (2004). Family- centered service for children with cerebral palsy and their families: A review of the literatüre. Semin Pediatr Neurol, 11(1), 78-86.

Kırbaş, Z.Ö. \& Özkan, H. (2013). Down sendromlu çocukların annelerinin aile işlevlerini algılama ve sosyal destek düzeylerinin değerlendirilmesi. İzmir Dr. Behçet Uz Çocuk Hastanesi Dergisi, 3(3), 171- 180.

Kuhlthau, K. A., Bloom, S., Van Cleave, J., Knapp, A. A., Romm, D., Klatka, K. et al. (2011). Evidence for familycentered care for children with special health care needs: A systematic review. Acad Pediatr, 11, 136-143.

MacKean, G.L., Thurston, W.E. \& Scott, C.M. (2005). Bridging the divide between families and health professionals' perspectives on family- centered care. Health Expect, 8, 74-85.

Mpofu, E., Levers, L.L., Mpofu, K., Tanui, P. \& Hossain, Z. S. (2014). Family assessments in rehabilitation service provision. In M.J. Milligton\& I. Marini (Eds). Families in rehabilitation counseling: a community-based rehabilitation approach (pp.251-266). New York: Springer Publishing Company.

Newacheck, P. \& Kim, S. (2005). A national profile of health care utilization and expenditures for children with special health care needs. Arch Pediatr Adolesc Med, 159, 1017.

Piskur, B., Beurskens, A.J., Jongmans, M.J., Ketelaar, M., Norton, M., Frings, C.A. et al. (2012). Parents' actions, challenges, and needs while enabling participation of children with a physical disability: a scoping review. BMC Pediatr, 12, 177.

Ryan, N. P., Wade, J. C., Nice, A., Shenefelt, H., \& Shepard, K. (1996). Physical therapists' perceptions of family involvement in the rehabilitation process. Physiother Res Int, 1(3), 159-179.

Schmidt, L.J., Garrat A.M. \& Fitzpatrick, R. (2002). Child/parent- assessed population health outcome measures: a structured review. Child Care Health Dev, 28, 227-237.

Yıldırım, A. \& Şimşek, H. (2011). Sosyal bilimlerde nitel araştırma yöntemleri. Ankara: Seçkin Yayınevi. 